\title{
América Latina: fronteiras e horizontes comuns da Educação em Direitos Humanos
}

\author{
Carlos Santander \\ Doutor em Ciências Sociais pela Universidade de Brasília. Professor \\ na Universidade Federal de Goiás, Goiânia, Goiás, Brasil \\ csantander@hotmail.com \\ Ricardo Barbosa de Lima \\ Doutor em Desenvolvimento Sustentável pela Universidade de Brasília. Professor \\ na Universidade Federal de Goiás, Goiânia, Goiás, Brasil \\ ricardo.ufg@gmail.com \\ Solon Eduardo Annes Viola \\ Doutor em História pela Universidade do Vale do Rio dos Sinos. Professor \\ na Universidade do Vale do Rio dos Sinos, São Leopoldo, Rio Grande do Sul, Brasil \\ solonv@unisinos.br
}

$\mathrm{O}$ presente número da revista Sociedade e Cultura, da Faculdade de Ciências Sociais da Universidade Federal de Goiás, trata da Educação em Direitos Humanos (EDH), tema cada vez mais significativo na América Latina e em especial no Brasil, que em 2003 instituiu o Plano Nacional de Educação em Direitos Humanos (PNEDH) e, em 2012, as Diretrizes Nacionais para a Educação em Direitos Humanos (DNEDH). Ambas as políticas públicas reconhecem a importância da educação para o exercício da cidadania e como eixo estruturador do sistema educacional.

No âmbito da América Latina, a proximidade geográfica, a história em comum e os objetivos compartilhados por seus países são componentes essenciais para se pensar a EDH e a região como um todo. Não é só a velha história de superação dos problemas associados aos processos de construção da identidade, das lutas pela independência, pela democracia, mas também o vínculo presente na busca da solução de problemas como a pobreza e a desigualdade estrutural que condicionam o futuro de nossas sociedades.

Cabe lembrar que, na década de 1960, a maioria dos países latino-americanos sofreu uma onda de autoritarismo, particularmente repressiva e dramática em termos de direitos humanos e de cidadania. Golpes militares instalaram-se, com diversos matizes e graus de violência, na Argentina (1962, 1966 e 1976), no Brasil (1964), no Peru (1968), no Uruguai (1973), no Chile (1973) e na Bolívia (1964 e 1971), enquanto outros países possuíam governos igualmente déspotas, como Paraguai, Equador, El Salvador, Guatemala, Honduras, Panamá, República Dominicana, Haiti e Nicarágua.

No Brasil, os primeiros debates sobre a Educação em Direitos Humanos, bem como as primeiras experiências, remontam à segunda metade da década de 1980, quando a sociedade brasileira movimentava-se para a superação do cerceamento à liberdade imposto pelo golpe militar 
de 1964 e pelo regime de terror de Estado que se seguiu. Cientes dos crimes contra a humanidade cometidos no período, grupos e entidades da sociedade civil iniciaram processos, eventos e programas de formação em direitos humanos. Isso se deu a partir do entendimento de que era urgente que cada brasileiro, cada brasileira, compreendesse que o ser humano é um ser de direitos, que precisa se reconhecer e ser reconhecido como tal, de modo a tornar possível a superação dos privilégios e dos preconceitos historicamente construídos e em seu lugar construir uma sociedade democrática capaz de, considerando suas diferenças, procurar a igualdade.

Tal como a Alemanha no pós-Segunda Guerra Mundial se perguntava como havia sido possível conviver com os campos de concentração e extermínio - dos quais Auschwitz tornou-se o maior exemplo - e as ditaduras da América Latina dos anos 1970, com seus centros clandestinos de extermínio - cujos exemplos incluem a Escola Superior da Armada na Argentina, o quartel do Doi-Codi de São Paulo e o quartel da Villa Grimaldi no Chile -, no Brasil a sociedade civil consideraria urgente, ao mesmo tempo, desvendar os segredos ocultos por setores do Estado e construir uma política de memória do passado para consolidar a proposta de Tortura Nunca Mais.

Foi esse o contexto em que, na década de 1980, com o fim do período ditatorial, se iniciaram na América Latina os processos de (re) democratização. Entre as múltiplas tarefas pendentes, as novas democracias latino-americanas tiveram de encarar as antigas violações dos direitos humanos, com contínuas consequências na contemporaneidade. Nesse sentido, os desafios presentes e futuros, no que diz respeito à preservação da memória histórica e à promoção dos direitos humanos e da cidadania, impõem a necessidade de criar-se um espaço latino-americano, na perspectiva de superar as fronteiras imaginárias na construção de uma compreensão integral do sentido de respeito à dignidade humana, em um horizonte comum.

As primeiras manifestações da sociedade civil resultaram na criação de diferentes tipos de organizações de defesa dos direitos humanos, tanto para a defesa da vida dos perseguidos políticos como para a criação de estratégias de defesa dos direitos civis e políticos da população. No caso do Brasil, organizaram-se manifestações contra a censura, em favor da anistia ampla geral e irrestrita, pelas eleições diretas e pela Constituinte livre e soberana. Entre esses movimentos, formaram-se grupos de professores que propunham atividades de Educação em Direitos Humanos.

Ações equivalentes foram desencadeadas em muitos países da América Latina, cresceram com a democratização e gradativamente tornaram-se temas de debates e pesquisas em muitas universidades do continente. Na Argentina, a Universidade Nacional de Quilmes (UNQ) propôs a criação da Rede Interamericana de Educação em Direitos Humanos (RIEDH), que começou a ser construída a partir do I Colóquio Interamericano sobre Educación en Derechos Humanos - "Experiencias, Problemas y Desafios", realizado em 2006 naquela instituição. A iniciativa teve como parceiros o Instituto de Derechos Humanos de la Facultad de Ciencias Jurídicas y Sociales de la Universidad Nacional de La Plata e o Instituto Interamericano de Derechos Humanos (IIDH). Dele participaram pesquisadores do Brasil, Uruguai, Chile, Paraguai, Costa Rica, México e Venezuela.

Em 2008, o II Colóquio Interamericano sobre Educación en Derechos Humanos - "La Práctica Educativa", também realizado na Universidad Nacional de Quilmes, em parceria com a Universidad de La 
Plata (UNLP), contou com novos integrantes, como a Asociación de Universidades Confiadas a la Compañía de Jesús en América Latina (AUSJAL); a Universidad Academia de Humanismo Cristiano (Chile) e o Centro de Derechos Humanos de la Universidad de Lanús (UNLa).

O III Colóquio Interamericano sobre Educación en Derechos $\mathrm{Hu}-$ manos - "Trajetórias, Fortalezas, Propuestas" foi realizado em maio de 2011. Nessa oportunidade foram organizadas 13 mesas temáticas, recebendo mais de cem trabalhos de várias cidades das distintas províncias da Argentina e do Paraguai, bem como do Chile, Costa Rica, Bolívia, Colômbia, Brasil, México, Portugal e Alemanha. A partir desse ano o Comitê Acadêmico decidiu pela internacionalização dos colóquios.

Assim, o IV Colóquio Interamericano sobre Educación en Derechos Humanos - "Experiencias Didáctico-Pedagógicas de la EDH: Aprendizajes y desafíos para la consolidación de una cultura respetuosa de los derechos humanos" ocorreu em setembro de 2012 na cidade de Santiago de Chile, com mais de 280 participantes. O evento, organizado pelo Instituto Nacional de Derechos Humanos de Chile e pela UNQ, contou mais uma vez com a presença de pesquisadores, organizações da sociedade civil, docentes, estudantes e instituições públicas e privadas de diversos países de América Latina.

O V Colóquio Interamericano sobre Educación en Derechos $\mathrm{Hu}-$ manos - "América Latina: fronteiras e horizontes comuns em EDH", realizado no Brasil, na Universidade Federal de Goiás, atraiu 450 pesquisadores de oito países (Chile, Uruguai, Costa Rica, Porto Rico, Bolívia, México, Argentina e Brasil), 144 trabalhos foram apresentados em 20 grupos de trabalho e contou com dez mesas-redondas, compostas por 26 especialistas convidados(as).

\section{Brasil e UFG}

$\mathrm{O} \mathrm{V}$ Colóquio Interamericano sobre Educación en Derechos $\mathrm{Hu}-$ manos, realizado na Universidade Federal de Goiás (UFG), teve como ponto central problematizar e avaliar os recentes avanços institucionais no campo da Educação em Direitos Humanos. O reconhecimento das convenções internacionais e o atendimento a algumas reivindicações anteriormente reprimidas fizeram a questão dos direitos humanos afirmar-se como política de Estado, o que estimulou diferentes governos nacionais a assumir, em outras frentes, o compromisso de implementar no país o Programa Mundial de Educação para os Direitos Humanos $(\mathrm{PMEDH})^{1}$ e seu respectivo Plano de Ação. ${ }^{2}$

$\mathrm{O}$ PMEDH defende que a promoção da Educação em Direitos Humanos permitirá ao sistema educacional alcançar sua principal missão: assegurar a educação para todos. ${ }^{3}$ Com base nesses instrumentos

1. Projeto Revisado de Plano de Ação para a Primeira Etapa (2005-2007) do Programa Mundial para a Educação em Direitos Humanos (ONU, AG, A/59/525/Ner.1, de 02/03). Tradução do autor.

2. Projeto Revisado de Plano de Ação para a Primeira Etapa (2005-2007) do Programa Mundial para a Educação em Direitos Humanos (ONU, AG, A/59/525/Rev.1, de 02/03). Tradução própria.

3. O PMEDH (2005/2007) tem como objetivos específicos: contribuir para o desenvolvimento de uma cultura de Direitos Humanos; promover o entendimento comum, com base em instrumentos internacionais, princípios e metodologias básicas para a Educação em Direitos Humanos; assegurar que a Educação em Direitos Humanos receba a devida atenção nos planos regional, nacional e internacional; proporcionar um marco coletivo comum para a adoção de medidas a cargo de todos os agentes pertinentes; ampliar as oportunidades de 
e em recomendações internacionais, foi instituído no Brasil o Comitê Nacional de Educação em Direitos Humanos (CNEDH) e aprovou-se o Plano Nacional de Educação em Direitos Humanos (PNEDH) em um contexto em que a temática dos direitos humanos adquiriu elevada significação histórica, como resposta à extensão das formas de violência social e à política vivenciada nas décadas de 1960 e 1970 (PNEDH, 2006, p. 22).

A UFG assumiu o compromisso de sediar o V Colóquio em função de seus 13 anos de institucionalidade no campo da EDH, haja vista que, já em 1999, por meio da Pró-Reitoria de Extensão e Cultura (PROEC), a UFG lançou seu Programa de Direitos Humanos e em 2010 reconheceu-o como Núcleo Interdisciplinar de Estudos e Pesquisas em Direitos Humanos (NDH), vinculado diretamente à Pró-Reitoria de Pesquisa e Pós-Graduação. Entre as diversas ações de ensino, extensão e pesquisa realizadas desde então pelo NDH/UFG, cabem destacar os quase 2.000 profissionais participantes de diferentes cursos de formação de formadores (extensão, aperfeiçoamento, especializações e mestrado acadêmico interdisciplinar em Direitos Humanos/PPGIDH) para qualificar agentes de segurança pública, professores, pesquisadores, comunicadores e defensores de direitos humanos. Também, desde 2009, o NDH/UFG promove anualmente seu seminário nacional "Pensar Direitos Humanos", que em suas três primeiras edições reuniu mais de 600 pesquisadores de todas as regiões brasileiras, de outros países latino-americanos e do velho continente.

Dessa forma, a organização do V Colóquio Interamericano de EDH, seminal iniciativa coordenada pela Universidade Nacional de Quilmes (UNQ), absorveu em seu âmbito o IV Pensar Direitos Humanos, permitindo ao NDH/UFG não só manter a periodicidade de seu principal evento, como também mostrar a força do ato pedagógico fundado nos princípios da reciprocidade, do reconhecimento e da união de esforços que só o trabalho em rede, dialógico e colegiado, permite. Ao mesmo tempo que a Rede Interamericana de Educação em Direitos Humanos (RIEDH) compromete o envolvimento de mais uma instituição parceira, a UFG, ela reconhece e fortalece o trabalho de mais de uma década do NDH/UFG no campo da Educação em Direitos Humanos.

\section{Dossiê EDH}

O presente dossiê relaciona seis artigos apresentados no V Colóquio Interamericano de Educação em Direitos Humanos, realizado no período de 11 a 13 de setembro de 2013 em Goiânia. A escolha dos artigos foi submetida a um duplo controle de qualidade: no primeiro, feito pelos organizadores deste número, foram seguidos critérios acadêmicos (o rigor e a profundidade dos textos selecionados) e geográficos (a cobertura do maior número possível de países participantes do Colóquio). No segundo, esse conjunto de artigos sofreu o processo de avaliação por pares, imposto pelo rigoroso comitê de pareceristas da revista Sociedade e Cultura.

Por certo, outros textos apresentados no V Colóquio/IV Pensar poderiam compor este número com a mesma profundidade dos que 
estão aqui publicados, mas, como ocorre em toda revista, estamos limitados pelo espaço da publicação. Informamos aos leitores interessados que os demais textos serão publicados em livro a ser organizado, ainda em 2014, pela UFG e pela UNQ.

$\mathrm{O}$ artigo que abre a série, "La institucionalización de la educación en derechos humanos en América Latina: avances, desafíos y una propuesta de prioridades", é de responsabilidade de Ana Maria Rodino. ${ }^{4}$ Em seu artigo, Rodino, baseada em mais de dez anos de pesquisa sobre a Educação em Direitos Humanos, descreve e revisa criticamente os avanços sobre o tema na América Latina, apontando as dificuldades a ser enfrentadas no futuro mais imediato ou mais distante. Sobre os avanços, destaca que os temas dos direitos humanos e da democracia estão cada vez mais presentes na educação dos diversos países da América Latina, nos diferentes níveis de ensino. Salienta, também, a importância dos avanços na elaboração de metodologias de ensino baseadas nos princípios dos Direitos Humanos.

Ao exercitar a difícil ação de pensar o futuro criticamente, Rodino propõe a busca de acordos pedagógicos que permitam construir estratégias semelhantes que aproximem educadores e pesquisadores latino-americanos tanto para conhecer como para ensinar Direitos Humanos em um continente tão carente deles. A autora destaca, entre outras, duas dificuldades centrais: a ausência de políticas públicas para a Educação em Direitos Humanos e a necessidade de formação de professores para os diferentes níveis de ensino.

O artigo de Antônio Carlos dos Santos, 5 "Humanidades: o lado humano da ciência", reconstitui, a partir de uma clivagem interdisciplinar, o debate entre o conhecimento científico e a importância das ciências humanas e dos diferentes modelos de desenvolvimento. Critica o modelo baseado no desenvolvimentismo econômico e hegemonizado pelo mercado e recupera questões fundamentais do humanismo, como o pressuposto da emancipação e da autonomia como forma de produzir uma sociedade socialmente justa, economicamente equilibrada e culturalmente fraterna. Ao criticar o período do desenvolvimentismo autoritário e predatório, afirma que "só poderá haver desenvolvimento científico com o desenvolvimento humano". De sorte que, ao analisar a sociedade atual - hegemonizada pelo mercado - e o papel massificador dos meios de comunicação de massa e da indústria cultural - como componentes da desigualdade social -, o autor pondera que "a percepção deste problema é fundamental para retomar o élan perdido historicamente: a mudança do quadro de exploração socioeconômica passa pelo papel das Humanidades no seio da sociedade".

O texto de Luísa Ripa, ${ }^{6}$ intitulado "Fronteras y horizontes que nos dan que pensar en los tiempos de la educación en derechos humanos", foi apresentado na conferência de abertura do V Colóquio. Fundamentada, entre outros, no pensamento de Gadamer, Ricouer e Dussel, a autora compreende a Educação em Direitos Humanos como uma possibilidade de avançar sobre as fronteiras que separam os povos, as comunidades e os indivíduos. Criticado o autoritarismo tão presente em nossa América, recupera o ideal da "Pátria Grande" latino-americana e propõe que a educação em e para "lós derechos humanos tendrá que ser: una educación sensible a la diferencia. Pero,

\footnotetext{
4. Professora doutora do Instituto Interamericano de Direitos Humanos da Costa Rica (IIDH).

5. Professor doutor da Universidade Federal de Sergipe.

6. Professora doutora da Universidade de Quilmes, Argentina.
} 
también, una educación sensible a la uniformidad y a los deseos de no diferenciarse. Una educación sensible a las tensiones y a los conflictos: de derechos, de valores, de intereses, de perspectivas [...]. Sensible a los problemas, sin tratar de minimizarlos ni sucumbir ante ello".

O quarto artigo é de autoria de Mariana Blengio Valdés ${ }^{7}$ e tem por título "La protección jurídica del derecho humano a la educación y su proyección en el ámbito internacional". Nele a autora faz um mapa dos avanços da Educação em Direitos Humanos, tomando como referência a proposta da Organização das Nações Unidas para a década da educação (1994-2004) e destaca o papel de organizações internacionais, como a Unesco e seu Plano Mundial de Educação em Direitos Humanos. Ressalta, também, os avanços na América Latina, especialmente quanto à incorporação do tema à legislação dos países da região. Não deixa de citar o pioneirismo do Plano Nacional de Educação em Direitos Humanos editado no Brasil em 2003 como uma política pública do Estado brasileiro. Para a autora, a Educação em Direitos Humanos permite desenvolver um campo novo da educação, marcado pela possibilidade de apreender a realidade: "La educación en derechos humanos supone la proyección de una cultura capaz de incorporar en la mente $\mathrm{y}$ en el accionar de las personas los principios que hacen a su esencia humana entre los cuales la autonomía constituye un rasgo esencial".

O texto de Miguel Rábago Dorbecker, ${ }^{8}$ intitulado "Interculturalidad, universidad y movimientos sociales latinoamericanos. Ideas desde la frontera norte", dedica-se a traçar um amplo panorama dos movimentos estudantis, estabelecendo elos entre as ações do movimento de 1968 e os movimentos latino-americanos atuais. Demonstra que as universidades latino-americanas, como as europeias e norte-americanas de meados do século passado estão comprometidas com a manutenção da hierarquia social e do conhecimento. Destaca, especialmente, a compreensão de que os movimentos atuais incluem "dentro de su propuesta de cambio interno/externo una reivindicación de educación intercultural" que possibilite não só a revisão de um modelo eurocêntrico de conhecimento, mas, especialmente, que a universidade possa, para além do discurso, ser um lugar multicultural que possibilite a relação simétrica e igualitária entre as diferentes culturas que compõem nosso continente e a sociedade humana em todo o globo.

O último artigo sobre o tema da Educação em Direitos Humanos é da autoria de Vera Maria Candau e traz como título "Professores/ as: multiplicadores de Educação em Direitos Humanos". A autora reconhece os avanços feitos em Educação em Direitos Humanos por meio de ações de Estado e de organizações da sociedade, mas destaca que ainda estamos no início dos debates sobre o tema, de modo que é possível "afirmar que ainda é frágil e pouco frequente a discussão sobre esta incorporação e a reflexão sobre o sentido da educação em direitos humanos nas nossas instituições educativas".

Destaca, também, que uma das maiores dificuldades que nossa sociedade encontra é o reconhecimento dos direitos humanos como um componente curricular em todo o sistema de ensino e que a Educação em Direitos Humanos "supõe processos multidimensionais e diversificados, orientados à construção de sujeitos de direito, cidadãos e cidadãs

\footnotetext{
7. Professora doutora. Cátedra Unesco de Educação em Direitos da Universidade da República, Uruguai.

8. Professor doutor da Universidade Iberoamericana, México.

9. Professora doutora da Pontifícia Universidade Católica do Rio de Janeiro, Brasil.
} 
participativos e comprometidos com a construção democrática em todos os âmbitos sociais".

As questões que o V Colóquio Latino-Americano debateu, e das quais o leitor tem nesta revista Sociedade e Cultura uma amostra, pretendiam, como pretende este número, favorecer os debates ainda recentes, mas já com um referencial crítico e propositivo, sobre a sociedade e os caminhos percorridos para a consolidação da democracia e dos direitos humanos no continente. Especialmente, trata da contribuição da educação como um elemento fundamental para a construção de uma cultura de direitos humanos.

Cada um dos textos trata das questões próprias das experiências nacionais de cada autor, mas não se reduzem a essas dimensões. Ao contrário, rompem as fronteiras do nacional e dão ao tema as dimensões que carrega consigo.

Os textos não se recusam a apontar problemas nem mesmo evitam críticas, mas não se negam a indicar caminhos, ao mesmo tempo universais e multiculturais, como precisam ser as abordagens sobre os direitos humanos. Orientam-se sempre para o reconhecimento do outro, a formação da cidadania ativa e a participação nos processos de democratização pelos quais passa o continente. Não desconhecem os fundamentos históricos dos direitos humanos: a igualdade, a liberdade e a fraternidade, e ao mesmo tempo compreendem que a América Latina é o continente das diferenças culturais e étnicas que nem sempre são reconhecidas, aceitas e incorporadas.

Por fim, e reafirmando o convite à leitura, os textos indicam que a Educação em Direitos Humanos não é um modismo nem mesmo uma tarefa fácil, e sim um projeto que vai além do simplesmente conhecer. Ao contrário, é preciso compreendê-los, respeitá-los e torná-los prática social solidária e livre que precisamos apreender cotidianamente.

Goiânia, dezembro de 2013 